\section{Intoxicacion aguda acuosa}

\section{Sr. Director:}

Benavente y col. plantean dos nuevas aportaciones al caso: a) Que la paciente pudo tener una alteración del osmorreceptor (reset osmostat) y b) Que no se puede diagnosticar Síndrome de Secreción Inadecuada de ADH (SSIADH) en caso de estrés (1).

Nuestra paciente no ha tenido un SSIADH clásico, trastorno crónico para el que sirven los criterios diagnósticos citados (2), como queda de manifiesto en el artículo. Tuvo un episodio, de horas de duración, de intoxicación aguda acuosa, que atribuimos a secreción inadecuada de $\mathrm{ADH}$ temporal (no a un SSIADH clásico), producido precisamente por estrés, junto con ingesta acuosa excesiva. Esta alteración se corrigió espontáneamente en menos de 24 horas.

Además, los autores consideran que la eliminación de agua mayor del $80 \%$ en 4 horas con osmolalidad urinaria baja, en la prueba de la Sobrecarga de Agua (SOA), cumple uno de los criterios de alteración del osmorreceptor (3). Sin embargo, olvidan que ésos son también los valores de la prueba en las personas sin alteraciones en el balance acuoso, como le ocurría a nuestra paciente a los 4 días del episodio agudo, momento en el que se realizó dicha prueba. Para considerar la alteración del osmorreceptor (que es un trastorno crónico como el SSIADH), falta el criterio diagnóstico básico: hiponatremia mantenida (4-5); tras el episodio agudo y sin mediar intervención terapéutica la paciente tenía en el momento de iniciar la SOA un Na de 141 y una osmolalidad plasmática de 283.

\section{T. López del Val, D. del Olmo, J. Diago, V. Alcázar}

Sección de Endocrinología y Nutrición. Hospital Severo Ochoa. Leganés. Madrid

1. Benavente Fernández A, Pérez Ramos MA, Romero-Jiménez MJ, Barrios Merino A. Reset osmostat o alteración del osmorreceptor. An Med Intern (Madrid) 2001; 18: 606.

2. Moses AM, Streeten DH. Trastornos d la neurohipófisis. En: Harrison. Principios de Medicina Interna. Fauci, Braunward, Isselbacher, Wilson, Martin, Kasper, Hauser, Longo, editores. 14 ed. Mcgraw-Hill Interamericana de España. Madrid 1998; 2276-2286.

3. Wall BM, Crofton JT, Share L. Chronic hyponatremia due to resetting of the osmostat in a patient with gastric carcinoma. Am J Med 1992; 93 (2): 223-8.

4. Saghaf1 D. Water loading test in the reset osmostat variant of SIADH. Am J. Med. 1993; 95 (3): 343.

5. Rose BD. Treatment of hyponatremia: SIADH and reset osmostat. UpToDate 2001; 9: 1 .

\section{Síndrome maligno por neurolépticos}

\section{Sr. Director:}

El síndrome maligno por neurolépticos (SMN), se caracteriza por hipertermia, alteración del nivel de conciencia, rigidez muscular y signos de disfunción autonómica. Se desarrolla con el tratamiento previo de fármacos, sobre todo neurolépticos. La incidencia es variable, oscilando entre el 0,07 y $2,4 \%(1,2)$, según los diferentes criterios empleados, tipo de estudio y población considerada. La mayoría de los autores consideran que los neurolépticos son causa necesaria pero no suficiente para desencadenar el proceso. Se han señalado diversos fármacos como coadyuvantes en el desarrollo del SMN, tales como litio, antidepresivos tricícli- cos, IMAO. Así como una serie de situaciones previas o factores predisponentes como deshidratación, infecciones, problemas orgánicos cerebrales previos, temperatura ambiental elevada, envejecimiento, hipotiroidismo, ferropenia, desnutrición, aumento o supresión brusca de fármacos antiparkinsonianos y antecedentes de episodios previos de SMN $(2,3)$.

Paciente de 57 años con antecedentes psiquiátricos de larga evolución. Unos 3 días antes de su ingreso comenzó un nuevo tratamiento con carbonato de litio $800 \mathrm{mg}$ al día, levopromazina $25 \mathrm{mg}$ al día, haloperidol $3 \mathrm{mg}$ al día, Clotiapina $40 \mathrm{mg}$ al día y biperideno $4 \mathrm{mg}$ al día. Fue traído a urgencias por cuadro de pérdida de conocimiento, caída la suelo, rigidez, convulsiones generalizadas tonicoclónicas, trismo y relajación esfinteriana. Según sus familiares había tenido en la horas previas cefalea y vómitos. A su ingreso se encontraba en situación postcrítica con aceptable estado general, algo desorientado espacialmente, facies amímica y seborreica, con fasciculaciones palpebrales y peribucales, movimientos oromandibulares, y temblor fino de carácter intencional en las extremidades superiores. La fuerza y la movilidad estaba conservada, no tenia rigidez de nuca, reflejo cutáneo plantar en flexión. La tensión arterial era de 140/90 mmHg, taquicardia a 120 pulsaciones por minuto y la temperatura axilar era de $37,8^{\circ} \mathrm{C}$. El resto de la exploración física no mostró alteraciones.

Exploraciones complementarias: leucocitos $20.300 / \mathrm{mm}^{3}$, recuento de $92 \mathrm{~N}, 4 \mathrm{~L}, 3 \mathrm{M}$, $1 \mathrm{~B}$, el resto del hemograma era normal. En la bioquímica: glucosa $112 \mathrm{mg} / \mathrm{dl}$, ácido úrico $8,2 \mathrm{mg} / \mathrm{dl}$, potasio 3,3 mEq/l, CK $751 \mathrm{U} / 1$, LDH $529 \mathrm{U} / 1$. Resto con urea, creatinina, colesterol, triglicéridos, bilirrubina total y directa, albúmina, proteínas totales, GOT, GPT, GGT, fosfatasa alcalina, calcio, cloro, fósforo y sodio eran normales. La serología a brucela, salmonella tiphi y paratiphi A y B, virus de la hepatitis B y C y VIH fueron negativas. Litemia 0,28 mEq/l (normal). Punción lumbar: glucosa $96 \mathrm{mg} / \mathrm{dl}$, proteinas $30 \mathrm{mg} / \mathrm{dl}$, LDH $164 \mathrm{U} / \mathrm{l}$. Recuento hematíes $217 / \mathrm{mm}^{3}$, leucocitos $2 / \mathrm{mm}^{3}$. La tinción de GRAM y el cultivo fueron negativas. Estudio de coagulación con actividad de protombina $72 \%$ y TTPa de 26 segundos. Orina y sedimento: indicios de proteinas, hematíes de 6 a 8 por campo, escasos restos de cilindros granulosos. La serología para conectivopatía con ANA y antiDNA era negativa.

La radiografía de tórax no mostró ninguna anomalía. ECG a su ingreso: taquicardia sinusal a 114 con eje normal. T.C craneal: realizado sin contraste, marcada atrofia cortico subcortical. Ensanchamiento del asta frontal derecha en relación con cavidad porencefálica adyacente, probablemente lesión hemorrágica antigua. Infarto lacunar antiguo. Hipodensidad de sustancia blanca periventricular.

En las horas posteriores, apareció fiebre de $38,6^{\circ} \mathrm{C}$, disminución del nivel de conciencia que llegó a coma profundo, deterioro de la función renal con urea de $160 \mathrm{mg} / \mathrm{dl}$ y creatinina $2,0 \mathrm{mg} / \mathrm{dl}$, oscilaciones en las cifras de la tensión arterial, crisis oculógiras, y variaciones en el nivel de conciencia, pasando del coma profundo a episodios de agitación, junto con la aparición de un reflejo cutáneo plantar en extensión, descenso de las cifras de hematíes y hemoglobina por una hemorragia digestiva.

El paciente recibió un tratamiento inicial con fluidoterapia, oxigeno, fenitoina, cefotaxima, y posterior con dantroleno, somatostatina, omeprazol y transfusión de concentrados de hematíes. Sus familiares solicitaron el alta voluntaria por extrema gravedad al tercer día de ingreso. Desconocemos su evolución posterior.

La primera descripción del SMN fue en 1968 por Delay y Deniker $(1,2,4)$, su diagnóstico es clínico, debiéndose de excluir sobre todo las causas de fiebre. Se consideran válidos los criterios de Levenson (5), Pope (6) o Adityanjee (7). El diagnóstico diferencial es amplio, debe de establecerse principalmente con el golpe de calor, la catatonia letal, la hipertermia maligna, el síndrome anticolinérgico central, síndrome serotoninico, intoxicaciones por litio, IMAO, estricnina y enfermedades que cursen con hipertonia o rabdomiolisis $(2,3)$. 
En nuestro paciente existían unos factores predisponentes para el desarrollo de SMN, tales como la existencia de una enfermedad orgánica cerebral, el cambio reciente de medicación con el añadido a la medicación antipsicótica de carbonato de litio. El cuadro clínico comenzó de manera brusca, desarrollándose por completo en unas 72 horas. Su inicio fue un poco atípico con la instauración de una crisis convulsiva, pero su posterior desarrollo fue típico de SMN con la aparición de fiebre, oscilaciones en el nivel de conciencia, elevación de las cifras de CK, deterioro de la función renal. Tuvo además algunas manifestaciones clínicas consideradas infrecuentes como las convulsiones, crisis oculógiras, trismo y signo de Babinski, sin embargo no presentó una clara rigidez, que atribuimos al tratamiento con fenitoina y posteriormente con dantroleno.

Las complicaciones más frecuentes del SMN son: insuficiencia respiratoria secundaria a hipoventilación, neumonía por aspiración, arritmias cardiacas, infarto agudo de miocardio, colapso cardiovascular, insuficiencia renal aguda secundaria a rabdomiolisis y mioglobinuria, insuficiencia hepática, tromboembolismo pulmonar, coagulopatía de consumo y sepsis. El SMN tiene una mortalidad del 20-30\% de los casos $(2,8)$, la mortalidad se debe a deshidratación, aspiración, hipotensión o fallo respiratorio. El riesgo de muerte o lesión cerebral aumentan con el tiempo de hipertermia.

\section{J. N. Alcalá Pedrajas}

Servicio de Medicina Interna. Hospital Comarcal Valle de los Pedroches. Pozoblanco. Córdoba

1. Rivera JM, García-Bragado F, Iriarte LM, Lozano Gutiérrez F, Salgado $\mathrm{V}$, Andreu J, et al. Síndrome neuroléptico maligno. Análisis de 9 casos. Med Clin (Barc) 1990; 94: 121-5.

2. Martínez E, Domingo P, Lloret J. Sindrome neuroléptico maligno. Med Clin (Barc) 1994; 102: 181-8

3. Segado Soriano A, López Glez-Cobos C, Villalba García MV, Gil Gómez J, Muiño Miguez A, Millán Núñez-Cortes J. Síndrome neuroléptico maligno. An Med Interna (Madrid) 1997; 14: 231-5.

4. Guzé BH, Baxter LR. Neuroleptic malignant syndrome. N Engl J Med 1985; 313: 163-6.

5. Levenson JL. Neuroleptic malignant syndrome. Am J Psychiatry 1985; 142: 1137-45.

6. Pope HG, Keck PE, McElroy SL. Frecuency and presentation of neuroleptic malignant syndrome in a large population hospital. Am J Psychiatry 1986; 143: 1227-33.

7. Adityanjee MD, Singh S, Singh G, Ong S. Spectrum concept of neuroleptic malignant syndrome Br J Psychiatry 1988; 153: 107-11.

8. Usandizaga I, Pérez de Mendiola MM, Buades J, Martínez J. Sindrome neuroléptico maligno. Med Clin (Barc) 1990; 95: 437.

\section{Hipertensión portal como complicación de hidati- dosis hepática}

Sr. Director:

Aproximadamente el $75 \%$ de los quistes hidatídicos que se desarrollan en el hombre producidos por las larvas del Echino coccus granulosus asientan en el hígado. Excepto cuando se complican por su infección o rotura, es habitual que evolucionen de una forma paucisintomática durante largo tiempo. Sin embargo, cuando se localizan próximos al hilio hepático, pueden comprimir o abrirse a los conductos biliares principales y causar ictericia. De forma excepcional, se ha descrito también la aparición de hipertensión portal (1-3); una manifestación, por el contrario, frecuente en la forma alveolar (4), producida por E. multilocula ris, y en las poliquísticas (5), debidas a E. vogeli y oligarthrus, que no suelen observarse en nuestro entorno.

Describimos el caso de un paciente con hidatidosis hepática múltiple e hipertensión portal de aparente mecanismo compresivo, que desarrolló varices esofágicas, hemorragia digestiva grave y una coagulopatía de consumo de evolución fatal.

Se trataba de un varón de 77 años que consultó por un cuadro de hemorragia digestiva en forma de hematemesis y melenas. Negaba ingesta habitual de alcohol y había sido sometido a una colecistectomía 20 años antes. En los últimos 4 meses seguía un tratamiento con $150 \mathrm{mg}$ diarios de aspirina, prescrito tras haber presentado episodios recurrentes de mareo y náuseas, que en alguna ocasión se acompañaron de enrojecimiento y prurito generalizado. En la exploración física se objetivaba palidez cutánea, una tensión arterial de $90 / 60 \mathrm{~mm} \mathrm{Hg}$ y una frecuencia cardíaca de 100 latidos por minuto. No existían visceromegalias o estigmas de hepatopatía crónica. De sus datos analíticos destacaban una cifra de hemoglobina de $8,2 \mathrm{~g} / \mathrm{dl}$ y una eosinofilia absoluta de 1.600 por $\mu \mathrm{L}$. La bioquímica general y hepática era normal, excepto el nivel de gammaglutamil-transpeptidasa de 59 UI/L (normal hasta 43). Una endoscopia digestiva demostró la existencia de cuatro cordones varicosos (grado III) en los dos tercios inferiores del esófago y abundante contenido hemático, que dificultaba la identificación del origen del sangrado. Una ecografía abdominal descubrió la presencia de una lesión quística de 8 $\mathrm{cm}$ de diámetro en el lóbulo hepático derecho y dilatación de la vena porta y sus ramas intrahepáticas izquierdas. La tomografía computarizada confirmó el hallazgo de una masa quística compleja que se situaba en los segmentos hepáticos 6,7 y 8 , con otras imágenes quísticas a su alrededor, que se extendían hasta el hilio hepático. La vena porta se visualizaba con dificultad y en el mismo hilio se observaban unas formaciones nodulares, sugerentes de una cavernomatosis portal. Se practicó un estudio angiográfico portal que mostró la permeabilidad del eje esplenoportal, así como una compresión extrinseca del tronco de la porta derecha con un flujo hepatofugal, a través de la vena coronaria-estomáquica. La serología para hidatidosis fue positiva con un título de 1/6.400 y la cuantificación de IgE sérica total fue de 16.456 $\mathrm{VI} / \mathrm{mL}$ (normal hasta 100). Por el contrario, fueron negativos los anticuerpos antinucleares, antimitocondriales y antimúsculo liso, así como las serologías de virus de la hepatitis B y C. También fueron normales los niveles de factor reumatoide, ferritina, ceruloplasmina y $\alpha-1$-antitripsina. Desde su ingreso fue tratado con omeprazol y se controló la hemorragia digestiva. Tras establecerse el diagnóstico de hidatidosis hepática complicada con hipertensión portal por compresión extrínseca, se añadió al tratamiento albendazol a dosis de $400 \mathrm{mg}$ dos veces al día por vía oral. Así mismo, se programó una intervención quirúrgica, que tuvo lugar dos semanas después de haber iniciado este último. En la cirugía se procedió al vaciado y esterilización de las cavidades quísticas, observándose su intercomunicación. El estudio anatomopatológico del parénquima hepático circundante fue normal. En las primeras horas del postoperatorio se observó un sangrado abundante por los drenajes abdominales y datos de una coagulopatía de consumo grave, con 42.000 plaquetas por $\mu \mathrm{L}$, una actividad de protrombina reducida (INR 2,3), un tiempo parcial de tromboplastina de $244 \mathrm{sg}$ (control de $29 \mathrm{sg}$ ), fibrinógeno de $46 \mathrm{mg}$ por $\mathrm{dL}$ y productos de degradación del fibrinógeno muy elevados. A pesar de los repetidos intentos de hemostasia quirúrgica, las medidas intensivas de soporte hemodinámico y de corrección de la coagulopatía, el paciente falleció en situación de distrés respiratorio y shock refractario.

Se han descrito diversos mecanismos para explicar la hipertensión portal que puede originarse en pacientes con hidatidosis hepática: la compresión de la vena porta o sus ramas (6), como sucedió en nuestro caso, la obstrucción de la vena esplénica (con desarrollo de hipertensión portal segmentaria) $(3,7)$ a través de 